\title{
Minimalism and Evolution
}

\author{
Michael C. Corballis* \\ School of Psychology, University of Auckland, Auckland, New Zealand
}

Minimalism proposes that universal grammar (UG) is a characteristic of human thought, also known as I-language, whose main component is the operation Merge, providing for the generative and recursive properties of human thought and language. The complexity and diversity of human languages arises from a process of externalization, whereby internal thoughts are communicated and shared. A fundamental tenet of the Minimalism Program is that UG is uniquely human, emerging well after the evolution of our species, Homo sapiens. I argue instead that the essence of I-language lies in the ability to think about the non-present, as in mentally traveling in time and space, which has a long evolutionary history among animals that move. What may be special but perhaps still not unique to humans is the capacity to communicate our mental travels, as in the core linguistic property of displacement. Mental time travel, or more broadly imagination, is unbounded, and it is this that underlies the generativity of linguistic expression.

Keywords: gesture, imagination, language, mental time travel, minimalism, theory of mind, universal grammar

\section{INTRODUCTION}

OPEN ACCESS

Edited by:

Koji Fujita,

Kyoto University, Japan

Reviewed by:

Ina Bornkessel-Schlesewsky, University of South Australia, Australia Harumi Kobayashi,

Tokyo Denki University, Japan

*Correspondence: Michael C. Corballis m.corballis@auckland.ac.nz

Specialty section:

This article was submitted to

Language Sciences,

a section of the journal

Frontiers in Communication

Received: 03 April 2019

Accepted: 13 August 2019

Published: 28 August 2019

Citation:

Corballis MC (2019) Minimalism and Evolution. Front. Commun. 4:46. doi: 10.3389/fcomm.2019.00046
The sheer complexity of human languages creates severe difficulties for the understanding of how it evolved. Shortly after the publication of Darwin's (1859) famous treatise On the Origin of Species, the philologist Müller (1880) was quick to note language as the main obstacle to Darwin's theory: "... the one great barrier between brute and man is language. Man speaks, and no brute has ever uttered a word. Language is our Rubicon, and no brute will dare cross it (p. 403)." Much more recently, Christiansen and Kirby (2003) introduced an edited collection of articles on language evolution with a chapter entitled "Language Evolution: The Hardest Problem in Science?"

The most prominent linguist of modern times, Noam Chomsky, has also been skeptical of natural selection as an explanation of how language emerged, proposing instead that language emerged in a single step in our own species, Homo sapiens, within the past 100,000 years, well after that species itself emerged (e.g., Chomsky, 2010). The advent of language may therefore seem a miracle of Biblical proportions rather than a product of natural selection. Chomsky's views on language have nevertheless become simpler since the publication of Syntactic Structures (Chomsky, 1957). In The Minimalist Program (Chomsky, 2015b), the essence of language is effectively reduced to the single operation Merge, the basis of what he calls I-language, the internal process that allows elements to be merged recursively to build structures of any desired degree of complexity. Berwick and Chomsky (2016) suggest that this simplified theory helps resolve the evolutionary problem: they write that "... narrowly focusing the phenotype in this way greatly eases the explanatory burden for evolutionary theory-we simply don't have as much to explain, reducing the Darwinian paradox" (p. 11).

Chomsky (2015a) writes that I-language is a system of discrete infinity, through a computational process yielding an unbounded array of hierarchically structured expressions. It has two interfaces with other systems, a conceptual-intentional (CI) system and a sensory-motor (SM) system; the SM system effectively links it with motor outputs for expression, through either speech or sign 
language. I-language is then fundamentally a property of human thought, and is only incidental to language as communication. This further eases the burden of explaining the complexity of language, because much of that complexity arises in the translation from thought to expression, or what Chomsky calls externalization. As Chomsky (2015b) put it: "It is a familiar fact (sic) that that the complexity and variety of language appears to be localized overwhelmingly - and perhaps completely-in externalization (p. xi)." I-language itself is of primary interest, because it not only unites the 6,000 languages of the world, providing a universal grammar (UG), but also applies to human thought itself, accounting for unbounded nature of both thought and expressive language.

In spite of these moves toward a simpler account seemingly more compatible with evolutionary theory, Chomsky and colleagues continue to insist that I-language, or UG, is unique to humans. In their treatise "Why only Us?" Berwick and Chomsky (2016) write of the Minimalist Program that "there is no room in this picture for any precursor to language" (p. 71). Part of the argument for the late emergence of UG rests on archaeological evidence for symbolic thought within the past 100,000 years, including the fashioning of bodily ornamentation from shells, beads, or animal teeth, the emergence of sophisticated cave art, and a sudden advance in the level of technology (e.g., Hoffecker, 2005; Mellars, 2005). Tattersall (2012) emphasizes the seemingly miraculous transformation in human thinking:

Our ancestors made an almost unimaginable transition from a non-symbolic, non-linguistic way of processing information and communicating information about the world to the symbolic and linguistic condition we enjoy today. It is a qualitative leap in cognitive state unparalleled in history. Indeed, as I've said, the only reason we have for believing that such a leap could ever have been made, is that it was made. And it seems to have been made well after the acquisition by our species of its distinctive modern form (p. 199).

But do such miracles really happen?

\section{TOWARD A GRADUALIST ACCOUNT}

According to Darwin (1859), any complex system must be formed by "numerous, successive, slight modifications (p. 158)," and that any exception would refute his theory. If I-language (or UG) did indeed emerge in a single step, it may appear to provide the exception that Darwin feared. Some theorists have suggested that evolutionary mechanisms compatible with evolution might be found in more recent developments, like exaptations, spandrels, punctuated evolution, or evo-devo, but there is still serious doubt as to whether a complex system such as language could have evolved fully-fledged in a single step (Pinker and Bloom, 1990).

There remains some ambiguity as to whether the concept of Merge is sufficiently simple to constitute a "slight modification," as Berwick and Chomsky imply, or whether the cognitive shift is "a qualitative leap unparalleled in history," as Tattersall claims, in which case the evolutionary challenge remains. Either way, there seems no strong reason to suppose that it emerged in a single step.

In what follows, I suggest that the essence of I-language exists in what has been termed "mental time travel" (Tulving, 1985; Suddendorf and Corballis, 1997, 2007), and underlies the linguistic property of displacement, defined by Hockett (1960) as the ability "to talk about things that are remote in space or time (or both) from where the talking is going on." Bickerton (2014) has suggested that displacement provides "the road into language" (p. 93). Displacement is not mental time travel itself, but is rather the externalization of mental time travel. In the view developed here, then, the generativity of language comes not from some human-specific concept of UG, but from our mental time travels, or more generally from imagination, as explained below.

\section{Mental Time Travel}

The concept of mental time travel arose from Tulving's work on episodic memory, the capacity to re-experience personal events. Tulving's (2002) view on the emergence of episodic memory echoes Chomsky's account of the late arrival of UG itself:

Many non-human animals, especially mammals and birds, possess well-developed knowledge-of-the-world (declarative, or semantic, memory) systems and are capable of acquiring vast amounts of flexibly expressible information. Early humans were like these animals, but at some point in human evolution, possibly rather recently, episodic memory emerged as an "embellishment" of the semantic memory system (p. 7).

The notion of episodic memory, though, may be extended to the experience of imagined future episodes; that is, we can travel mentally both backward and forward in time (Suddendorf and Corballis, 1997, 2007), with the suggestion that mental time travel in general is unique to humans. Further, our displaced thoughts also go well-beyond the imagining of past or possible future events to events that are purely imaginary. Imagination itself may be defined as "the act or power of forming a mental image of something not present to the senses or never before wholly perceived in reality" (Merriam-Webster on-line Dictionary $)^{1}$. Imaginative thoughts carry the generativity and recursiveness exemplified in our reconstructions of the past, in mental anticipations of the future, and perhaps most commonly in the fabrication of stories (Boyd, 2009; McBride, 2014) that need not be specifically located in time ("Once upon a time."). Indeed it is stories, whether in the form of fiction, soap operas, tales around the campfire, or gossip, that prompted Niles (2010) to rename our species Homo narrans - the storytellers.

If mental time travel is indeed unique to humans, then this might help further explain why language itself is unique to humans. This tidy picture perhaps explains much that is distinctive to our species, but still leaves the question of how such far-reaching and complex activities could have evolved in such a short period of time, and in a single momentous step.

${ }_{1}^{1}$ Merriam-Webster Dictionary, online at https://www.merriam-webster.com/ dictionary/imagination 


\section{Is Mental Time Travel Really Unique to Humans?}

Claims that episodic memory (Tulving, 2002) and mental time travel more generally (Suddendorf and Corballis, 1997, 2007) are unique to humans were soon challenged. First off the mark were Clayton and Dickinson (1998), who provided evidence that scrub jays not only recalled where and when they had cached items of food, but also re-cached food in apparent anticipation that a bird watching the original caching might later steal the food. Similar behavioral claims for mental time travel have been offered for a wide variety of non-human species, including chickadees (Feeney et al., 2009), great apes (Martin-Ordas et al., 2010; Beran et al., 2012; Janmaat et al., 2014), meadow voles (Ferkin et al., 2008), rats (Bird et al., 2003; Wilson et al., 2013), ravens (Kabadayi and Osvath, 2017), scrub jays (Clayton et al., 2003), and even cuttlefish (Jozet-Alves et al., 2013). In one recent study, rats remembered many different episodes over intervals of up to 45 min without any evidence of decline in performance (PanozBrown et al., 2016).

This body of evidence is now substantial, although sometimes explicable in terms of processes other than mental time travel, such as trial and error learning or simple association (Suddendorf and Corballis, 2010). Additional evidence, though, comes from neurophysiology, leading me to change my opinion and argue that mental time travel probably goes far back in the evolution of animals that move around in space (Corballis, 2013; but see Suddendorf, 2013).

\section{Role of the Hippocampus}

It has long been known that the hippocampus is critical to human declarative memory, including semantic memory for general facts as well-episodic memory for specific events. Patients with bilateral loss of hippocampal function are well-known to suffer severe loss of episodic memory for past events, as well as an inability to form new memories (Corkin, 2002, 2013; Tulving, 2002; Wearing, 2005). Brain imaging confirms that the hippocampus is active both when people recall past episodes and when they imagine future ones (Martin et al., 2011), and also when they simply construct imaginary scenes (Hassabis et al., 2007). Although critical to the construction of imagined events, the hippocampus is probably part of a larger network; for example, impairment of the ability to imagine personal past or future events has also been linked to damage of the ventromedial prefrontal cortex (Bertossi et al., 2016). Maguire et al. (2016) suggest that the particular role of the hippocampus may lie in what has been termed scene construction, the drawing together of dispersed information for conscious inspection, while McCormick et al. (2018) suggest that hippocampal function goes beyond mental time travel to mind-wandering more generally, and lies at "the heart of mental life" (p. 2745).

Neurophysiological recordings from the rat hippocampus suggest remarkably similar functions. It has long been known that cells in the rat hippocampus, known as "place cells," record the animal's current location in space (O'Keefe and Nadel, 1978). While this suggested different roles for the hippocampus in humans and rodents, subsequent research has revealed increasing convergence. Place cells not only record current location, but may fire in sequence after an animal has been removed from the particular environment to which they corresponded, indicating memory for an earlier episode. Such sequences correspond to trajectories in the earlier environment, and have been described as "replays", although in many cases they did not correspond to trajectories actually taken, as though the animal was imagining future trajectories or simply mentally exploring. Reviewing the evidence, Moser et al. (2015) write that "the replay phenomenon may support 'mental time travel' ... through the spatial map, both forward and backward in time (p. 6)." And this evidence comes from the rat, contrary to Tulving's suggestion that mental time travel is uniquely human.

Again, many other brain regions seem to echo these trajectories (Hoffman and McNaughton, 2002), driven by the hippocampal sequences. Place cells respond not only to specific locations, but tag non-spatial features of past event even in the rat, such as odors (Igarashi et al., 2014), touch sensations (Young et al., 1994), and the timing of events. Hippocampus activity is modulated by activity in the neighboring entorhinal cortex, where so-called grid cells code locations corresponding to spatial features such as spatial scale and orientation, and other cells code shape and color, proximity to borders, and the direction in which the head is facing (Diehl et al., 2017). These cells operate in modular fashion, creating an enormous number of combinations reflecting the possible spatial contexts in which an animal might find itself. Moser et al. (2015) liken this to "an alphabet in which all words of a language can be generated by combining only 30 letters or less" (p. 11). The system is fundamentally generative.

Such properties seem to extend to imagined locations and trajectories as well as those recording the present. Drawing on both human fMRI evidence and neurophysiological recordings in rodents, Deuker et al. (2016) write of "an event based map of memory space in the hippocampus," scaled with "the remembered proximity of events in space and time" (p. 1). In one study, the rat hippocampus constructed 11 different maps of 11 different rooms in which it had previously been placed (Alme et al., 2014), suggesting the capacity to conjure different settings. In humans, this may underlie the capacity to hold stories in context. Milivojevic et al. (2018) show from brain imaging how people maintain separate episodic context for stories, even when the stories, shown as videos, are interwoven in time. Hippocampal function is both generative and recursive, as in the capacity to alter spatial scale, and zoom-effectively embedding finer-scaled representations into more global ones. Mental time travel itself is recursive, in that we can call routines representing past, future, or purely imaginary sequences of events and insert them into the present-and even insert scenes into scenes, as when we recall an event when we remembered another event. Even episodic memory itself is generative, a construction rather than an exact rendering of the past. As Neisser (2008) once put it, "Remembering is not like playing back a tape or looking at a picture; it is more like telling a story (p. 88)." Because of the vast number of objects, actions and qualities we know, and our ability to combine them into different combinations as remembered or imagined scenes, and locate them in time and space, imagination itself is essentially unbounded. 
So-called declarative memory, made up of both episodic and semantic memory, is widely understood to be dependent on hippocampal function (e.g., Squire, 2004), and the term "declarative" itself betrays the close relation between memory and language. Duff and Brown-Schmidt (2012) review evidence from studies of hippocampal amnesia that that the hippocampus is important in binding information from different sources and supplying a flexibility of operation required for coherent language. Piai et al. (2016) add evidence from recording of hippocampal theta during sentence processing, and suggest that the hippocampus should be considered part of the language network, a conclusion endorsed by Covington and Duff (2016). Individuals such with large-scale destruction of the hippocampus can retain the basic ability to speak, but loss of episodic memory, and of mental time travel more generally, severely restricts communicative content (Wearing, 2005; Corkin, 2013), and word learning becomes sparse and slow (Warren and Duff, 2019). Of course, the language network includes many other functions, such as word knowledge and syntax, and the hippocampus itself has functions independent of language, but normal language does seem to depend on it. Given that declarative memory includes episodic memory, we might conclude that mental time travel more generally can be considered part of the declarative system, accessible in humans through language. The hippocampus thus not only contributes to the generative and integrative aspects of language, but is also the mechanism for displacement, the power of language to refer to, or create, events removed from the present in time and space.

The suggestion here, then, is that the essential properties of Ilanguage lie not in some uniquely human operation called Merge, but rather in the evolutionarily old faculty of imagination. I make no claim that imagination can be reduced to a function like Merge, or that there might be binary distinctions like that between internal and external Merge. This is perhaps something to be explored, but if the generative aspect of internal thought evolved gradually, rather than appearing uniquely in humans, there is no longer a pressure to minimalism. Our ability to conjure imaginary scenes may well-involve more than a single operation like Merge. For example, human imagination probably involves analog processes (Cooper and Shepard, 1984) as well as digital ones, against the spirit of Minimalist theory. Of course our imagination may be well more complex than in other species, such as the rat, because human culture has created a huge number of different objects, largely through manufacture, along with different operations that go with them, and imagination may also have spiraled into more abstract and complex forms.

Mental time travel, or imagination, involves both generative and memorial components, and the historian FernándezArmesto (2019) makes the interesting suggestion that human evolution traded one for the other. Humans, he suggests, have poorer memories than other primates, but instead have evolved the power to generate novel scenarios and creative ideas, perhaps as adaptations to the shift from a forested environment to the more uncertain world of the Pleistocene. This provides yet another claim for human uniqueness:
The degree to which humans are, as far as we know, uniquely creative seems vast by comparison with any of the other ways in which we have traditionally been said to excel other animals (p. 3).

A hint as to the early evolutionary origins of that creativity may nevertheless be discerned in the hippocampal trajectories recorded in the rat, and need not disconfirm Darwin's (1871) edict that "[The] difference in mind between man and the higher animals, great as it is, certainly is one of degree and not of kind (p. 126)." Even so, the generative component have well have expanded to the point of allow "discrete infinity," and perhaps helps explain why language itself evolved in the hominin line, and not in our close but largely forest-bound relatives, the apes.

In this account, though, the generativity of language lies not in language itself, but in the imagination that language is designed to express. As Pinker and Jackendoff (2005) remark, "the only reason language needs to be recursive is because its function is to express recursive thoughts (p. 230)." Similarly, Dor (2015) described language as "the instruction of imagination." This raises the question of how our internal thoughts are externalized, so they can be shared with others.

\section{EXTERNALIZATION}

Although minimalist theory puts little emphasis on it, externalization is a necessary aspect of communicative language, and raises further questions about human uniqueness. It is often claimed, for example, that only humans possess the necessary anatomical requirements for speech. In most mammals, the vocal system is relatively fixed, and used for instinctive calls signaling emotion, territory, or danger. Our closest non-human relatives, chimpanzees and bonobos, have some limited degree of intentional control over their vocalizations (e.g., Slocombe and Zuberbühler, 2005), but little evident capacity to produce or learn anything like spoken words, either in number or complexity. According to Petkov and Jarvis (2012), only parrots approach humans as "high vocal learners," with songbirds not far behind, while non-human primates are at best "limited vocal learners."

The production of articulate speech also required alterations to the vocal tract. The optimal configuration is a right-angled vocal tract with equal horizontal and vertical parts (Lieberman et al., 2002), which among primates seems to exist only in humans. In most other mammals the horizontal portion, including most of the tongue, is the longer, constraining the ability to create different sounds. The configuration appears to have been non-optimal even in Neanderthals and Denisovans, who were very nearly identical both genetically and in terms of brain size to Homo sapiens (Prüfer et al., 2014), even to the point that was some interbreeding between early humans and these species. Since diverging from these now-extinct species, humans underwent a flattening of the face that optimized the proportions of the vocal tract, and a recent study indicates that this was driven, not by a change in gene sequences, but by a change in gene regulation due to methylation (Gokhman et al., 2019). It is possible that the Neanderthals spoke (Dediu and Levinson, 2013), but probably less distinctly than Homo sapiens. 
Because voluntary control of vocalization in non-human primates is extremely limited, there must have been changes in neural connections in the course of hominin evolution to enable speech. Simonyan and Horwitz (2011) describe evidence that control of the laryngeal muscles from the premotor cortex is only indirect in non-human primates, but that in humans there are direct connections from the primary motor cortex to brain stem laryngeal muscles. Koda et al. (2018) report that Japanese macaque monkeys do have limited voluntary control over vocalization, but it is slow and evidently effortful. They note too that the emergence of direct connections from motor cortex to laryngeal muscles was still not sufficient for speech, which also required fine motor control of jaws, lips, tongue, and diaphragm - all of which constituted a "unique form of systems integration." These transformative changes presumably occurred late in the course of hominin evolution.

\section{Language as Gesture}

Evidence on the evolution of speech therefore lends some support to the idea that language itself evolved late in hominin evolution and was possibly unique to Homo sapiens, although it suggests a more gradual process than the single "great leap forward" endorsed by Chomsky (2007, p. 3). More importantly, it neglects the often-overlooked fact that language cannot be equated to speech. The signed languages invented by deaf communities have all of the essential properties of true language (e.g., Neidle et al., 2000; Emmorey, 2002). It has long been proposed that language evolved, not from vocal calls, but from manual gestures (e.g., de Condillac, 1971; Hewes, 1973; Armstrong, 1999; Corballis, 2002; Arbib, 2012). The gestural theory suggests that precursors to language may extent even further back in evolution, with vocal speech a much more recent development.

One platform for gestural communication may go back as far as our common ancestry with monkeys. So-called "mirror neurons" in the macaque brain respond both when the animal makes a grasping movement with the hand and when it watches another individual making the same movement, mapping input to output. These neurons are located in an area of the frontal lobe homologous with Broca's area in the human brain, leading Rizzolatti and Arbib (1998) to write of "Language within our grasp," suggesting a manual origin. Later research revealed a more extensive mirror system, again largely homologous with cortical language area in the human brain (Rizzolatti and Sinigaglia, 2010). I have speculated elsewhere as to how the mirror system fissioned and lateralized into different circuits, one of the being the language circuit (Corballis, 2017a). The mirror system in macaques is responsive to manual and facial actions, and even to the sound of those actions, but at best only weakly responsive to vocalizations themselves (Coudé et al., 2011), which again suggests the primacy of gesture in language evolution.

Great apes in the wild gesture prolifically to each other intentionally, in ways more language-like than their restricted vocal utterances (Pollick and de Waal, 2007). Byrne et al. (2017) report evidence for repertoires of at least 66 natural gestures in the chimpanzee, 68 in bonobos, 102 in gorillas, and 64 in orangutans, considerably larger than their repertoires of vocal calls. Many of those observed in the wild are common to the different species, suggesting that they are based on phylogeny rather than social learning, but they are also greatly augmented in the case of apes trained to use gestures or on a keyboard containing visual representations (lexigrams). The gorilla Koko, for example, is said to use and understand over 1,000 signs (Patterson and Gordon, 2001). The bonobo Kanzi uses a keyboard with 348 abstract symbols representing objects and actions, and augments his productive vocabulary with signs (Savage-Rumbaugh et al., 2004). Based on studies of gestural communication in apes, Tomasello (2008, p. 55) refers to gestures as "the original font from which the richness and complexities of human communication and language have flowed."

It seems likely that early communication of mental time travels was largely pantomimic, with remembered or planned actions acted out for relatively easy identification. There is some evidence for pantomime in non-human primates. Russon and Andrews (2001) identified 18 different pantomimes produced by orangutans in a forest-living enclave in Indonesia, 14 addressed to humans and four to fellow orangutans. These included mimed offers of fruit, enacting a haircut, and requests to have their stomachs scratched by scratching their own stomachs and then offering a stick to the prospective scratcher. A chimpanzee in the wild watched her daughter trying to use a stone to crack a nut, and then enacted the operation to show her how to do it properly (Boesch, 1993). Tanner and Perlman (2017) note that gorillas combine gestures in sequence creatively and interactively, although this seems to have more to do with play and personal display than with propositional communication, and may be the origin of music and dance rather than of language itself.

Pantomimic communication probably expanded early in the Pleistocene, which dates from about 2.6 million to about 11, 700 years ago, with the emergence of the genus Homo, characterized by a threefold increase in brain size, and a shift from facultative to obligate bipedalism, freeing the hands for more effective manual communication. Donald (1991) refers to the "mimetic culture" of the early Pleistocene. These developments in turn were probably driven by a switch from a forested habitat to the more open African savanna, and increasing dependence on communication to maintain social bonds, especially in the face of dangerous predators. As suggested earlier, this change in habitat may have driven the expansion of imagination itself, as it became increasingly important to share information about past and future, and improvise new plans and techniques. The emergent hunter-gatherer pattern resulted in long delays between the acquisition and the use of tools, as well as geographical distance between the sources of raw material for tools and killing or butchering sites (Gärdenfors and Osvath, 2010). The hunter-gatherer lifestyle involved frequent shifts of camp as resources were depleted, forcing the group to move on to another more abundant region-a pattern still evident in present-day hunter-gatherers (Venkataraman et al., 2017).

Pantomime probably did not give way to speech in a single step. Rather, vocalization was probably introduced gradually, and even today manual gestures typically accompany speech (Iverson and Goldin-Meadow, 1998). Caradec's (2005) dictionary of bodily gestures lists over 850 gestures from around the world 
that either accompany speech or can stand alone (excluding sign languages). Pantomime had the advantage of representing events in iconic fashion, but through conventionalization (Burling, 1999) gestures could be simplified in the interests of communicative efficiency, and could eventually include vocal sounds with little or no iconic reference. I have elaborated this scenario in more detail elsewhere (Corballis, 2017b).

\section{Theory of Mind}

The externalization of thought also depends on theory of mind, the understanding of what is in the recipient's mind. Thus, Chomsky (2007) argues that the elements of language are not what he calls "mind-independent entities" (p. 7 et seq), mapping onto aspects of the physical world. Rather, they map more or less directly to the mind, and include emotions and attitudes as much as physical objects and actions. As Chomsky put it, "communication depends on shared cognoscitive powers" (p. 10)-what's in the mind rather than what's in the world.

The understanding of what is in the minds of others has been termed "theory of mind." As the philosopher Grice (1989) pointed out, I cannot have a meaningful conversation with you unless I know what you are thinking, and know that you know that I know this. Recursion, therefore, comes from the mental processes rather than from language itself. The words we actually use are seldom if ever sufficient to convey precise information; we rely extensively and often unconsciously on shared streams of thought. The manner in which use shared knowledge to extract information from linguistic utterance is explored by Sperber and Wilson (2002). Words are effectively used not so much to refer to specific aspects of the world about us as to nudge shared trains of thought. The sharing of thoughts often depends on simple gestures rather than fully fledged language. Scott-Phillips (2015) gives the example of simply catching the eye of the waiter in a café with a nod to indicate that you would like a coffee refill.

Language, then, can be considered a sophisticated way of sharing thoughts, but it remains what Scott-Philips calls underdetermined. This is illustrated by the phenomenon of polysemy-many individual words have many different meanings, and need context and parallel trains of thought for the establishment of meaning. An extreme example is the word set; according to the Chambers Online Dictionary, it has 105 different meanings. And although expressive language can be complex and convoluted, its contribution to communication pales beside the role played by on-going thoughts that operate below the surface.

Scott-Philips suggests that it is underdeterminacy that makes language unique to humans, but this is questionable. Studies of gestural communication among chimpanzees in the wild are often highly variable, suggesting a lack of determinacy (Hobaiter and Byrne, 2011). De Waal (2019) gives an extraordinary and largely personal account of the subtle and human-like ways in which chimpanzees interact socially, and deplores the sanctions against anthropomorphism-he terms it anthropodenial - which may blind us to the ways in which other animals share thoughts and emotions. Monkeys also interact socially. Shepherd and Freiwald (2018) used whole-brain fMRI to examine the responses of face-to-face interaction in macaques, revealing a network that overlapped with the primate mirror system and with homologs of the human speech areas.

The broader question of whether non-human species are capable of theory of mind itself has been much discussed and disputed since Premack and Woodruff (1978) asked the explicit question "Does the chimpanzee have a theory of mind?" Thirty years later, Penn et al. (2008) argued that even chimpanzees, our closest non-human relatives, have no theory of mind, describing such attributions as "Darwin's mistake." In the same year, Call and Tomasello (2008) concluded, more generously, that the 30 years of research showed chimpanzees to have an understanding of the goals, intentions, perceptions, and knowledge of others, but no understanding of others' beliefs or desires. But even that claim may be too limited. A critical criterion for advanced theory of mind is that the individual shows understanding that another individual has a false belief. In a recent study, Krupenye et al. (2016) show that great apes, including chimpanzees, bonobos and orangutans look in anticipation of whether a human agent will falsely believe an object has been hidden. That is, they seem to pass the falsebelief test, often regarded as the gold-standard test of theory of mind (Wimmer and Perner, 1983). This study seems to join a chorus of studies gradually showing greater mental continuity between humans and other species than commonly assumed. If de Waal's account is correct, even this may underestimate great ape social intelligence.

\section{SUMMARY AND CONCLUSIONS}

Although this article goes beyond minimalism, it owes much to Chomsky's insights as to the nature of language. It accepts the notion that the basis of language is a mode of thought, which Chomsky calls I-language, and that spoken or signed languages emerge through a process of externalization. It accepts too the idea that the unbounded, generative nature of language is to be found in the underlying thought processes rather than in the externalized products-the 7,000 or so languages of the world. The much-disputed notion of universal grammar (UG), then, is in the structure of thought rather than in communicative languages themselves, with its universality deriving from commonalities of thought rather than in the multiplicity of actual grammars.

Minimalism, though, embeds these ideas in a formal framework, with little reference to biological naturalism. This perhaps reinforced the idea that language, whether as thought or as communication, is uniquely human, and quite different from anything evident in non-human species. In the account given here, I have tried to place Chomsky's insights as formulated in the Minimalist Program in a more naturalistic framework, which allows thought and language to be viewed in a broader perspective, with antecedents in various aspects of nonhuman behavior and biology. This in turn largely removes the pressure toward minimalism itself, so that thought and language can be understood in the wider context of animal behavior and evolution.

A more expansive view of I-language, then, is that it is largely captured in the internal process of imagination, itself a 
generative process that is unbounded, at least in humans. The essence of imagination lies in mental time travel, the internal ability to envisage events at other points in time and space, and indeed to create fictitious events. While it has been argued that mental time travel, like language itself, is uniquely human, evidence from animal behavior and neuroscience increasingly suggests evolutionary continuity. Imagination is a conserved and flexible system mapping onto the flux of experience, with its own combinatorial and recursive nature. Even rodents seem capable of generating mental time travels. Whether these mental travels can amount to discrete infinity is no doubt problematic, and the degree to which imagination is bounded may well have decreased over time.

A more naturalistic account of externalization also suggests continuity, and I have focused especially on the proposition that productive language emerged from manual gestures, and on theory of mind. Both have recursive properties that might map onto the recursive nature of imagination, but exactly how this is done might be a project, which I hesitate to call the Maximalist Project. My account is far from a finished product.

There remains the question of why expressive language does seem to be unique to humans, even if generative imagination is not. Evidence increasingly shows varied communication systems in other species-whales, birds, monkeys, bees, even ants-but so far there is little suggestion that any non-human animal can share their internal thoughts, or tell what they did yesterday or might do tomorrow. Perhaps it is for the most part adaptive

\section{REFERENCES}

Alme, C. B., Miao, C., Jezek, K., Treves, A., Moser, E. I., and Moser, M.-B. (2014). Place cells in the hippocampus: eleven maps for eleven rooms. Proc. Natl. Acad. Sci. U.S.A. 111, 18428-18435. doi: 10.1073/pnas. 1421056111

Arbib, M. A. (2012). How the Brain Got Language: The Mirror System Hypothesis. New York, NY: Oxford University Press.

Armstrong, D. F. (1999). Original Signs: Gesture, Sign, and the Source of Language. Washington, DC: Gallaudet University Press.

Beran, M. J., Perdue, B. M., Bramlett, J. L., Menzel, C. R., and Evans, T. A. (2012). Prospective memory in a language-trained chimpanzee (Pan troglodytes). Learn. Motiv. 43, 192-199. doi: 10.1016/j.lmot.2012.05.002

Bertossi, E., Tesini, C., Cappelli, A., and Ciaramelli, E. (2016). Ventromedial prefrontal damage causes a pervasive impairment of episodic memory and future thinking. Neuropsychologia 90, 12-24. doi: 10.1016/j.neuropsychologia.2016.01.034

Berwick, R. C., and Chomsky, N. (2016). Why Only Us? Language and Evolution. Cambridge, MA: The MIT Press.

Bickerton, D. (2014). More Than Nature Needs: Language, Mind, and Evolution. Cambridge, MA: Harvard University Press.

Bird, L. R., Roberts, W. A., Abroms, B., Kit, K. A., and Crupi, C. (2003). Spatial memory for food hidden by rats (Rattus norvegicus) on the radial maze: studies of memory for where, what, and when. J. Comp. Psychol. 117, 176-187. doi: $10.1037 / 0735-7036.117 .2 .176$

Boesch, C. (1993). "Aspects of transmission of tool-use in wild chimpanzees," in Tools, Language, and Cognition in Human Evolution, eds K. R. Gibson and T. Ingold (Cambridge: Cambridge University Press), 171-183.

Boyd, B. (2009). The Origin of Stories. Cambridge, MA: The Belknap Press of Harvard University Press. doi: 10.2307/j.ctvjf9xvk

Burling, R. (1999). "Motivation, conventionalization, and arbitrariness in the origin of language," in The Origins of Language: What Human Primates Can Tell Us, ed. B. J. King (Santa Fe, NM: School of American Research Press), 307-350. not to transmit such information-language causes almost as much mischief as benefit, through lying, defamation, and willful misinformation, and in any case even we humans keep most of our internal thoughts to ourselves. Perhaps the balance shifted in favor of sharing when our forebears moved from an enclosed forested habitat to a more open, expansive one leading to hunting, gathering, and migration. Instead of supposing that this happened within the past 100,000 years, we can more realistically consider the past 6 million years since our common ancestry with great apes, with perhaps the major focus on the past two to three million when our forebears became obligate bipeds, brain size underwent a dramatic increase, and the manufacture of tools became more advanced. Unfortunately, this was a period marked by the extinction of all hominin species except ourselves, so that critical biological information is lacking. All we have to go on is fossil evidence and, increasingly, ancient DNA.

Even so, it is surely unlikely that the critical changes that gave us expressive, generative language occurred in a single step within the last 100,000 years-unless there really was a miracle. We need to continue to probe closely into what happened biologically in those dark years between our great-ape ancestry and last extant hominin, our own species.

\section{AUTHOR CONTRIBUTIONS}

The author confirms being the sole contributor of this work and has approved it for publication.
Byrne, R. W., Cartmill, E., Genty, E., Hobaiter, C., and Tanner, J. (2017). Great ape gestures: intentional communication with a rich set of innate signals. Anim. Cognit. 20, 755-769. doi: 10.1007/s10071-017-1096-4

Call, J., and Tomasello, M. (2008). Does the chimpanzee have a theory of mind? 30 years later. Trends Cogn. Sci. 12, 187-192. doi: 10.1016/j.tics.2008.02.010

Caradec, F. (2005). Dictionnaire des Gestes. Attitudes et Mouvements Expressifs en Usage dans le Monde Entier. Paris: Fayard.

Chomsky, N. (1957). Syntactic Structures. The Hague: Mouton.

Chomsky, N. (2007). Biolinguistic explorations: design, development, evolution. Int. J. Philosoph. Stud. 15, 1-21. doi: 10.1080/096725506011 43078

Chomsky, N. (2010). "Some simple evo devo theses: how true might they be for language?," in The Evolution Of Human Language, eds R. K. Larson, V. Déprez, and H. Yamakido (Cambridge: Cambridge University Press), 45-62. doi: 10.1017/CBO9780511817755.003

Chomsky, N. (2015a). Some core contested concepts. J Psycholing. Res. 44, 91-104. doi: 10.1007/s10936-014-9331-5

Chomsky, N. (2015b). The Minimalist Program: 20th Anniversary Edition. Cambridge, MA: MIT Press. doi: 10.7551/mitpress/9780262527347.001.0001

Christiansen, M. H., and Kirby, S. (2003). "Language evolution: the hardest problem in science?," in Language Evolution, eds M. H. Christiansen and S. Kirby (Oxford: Oxford University Press), 1-15. doi: 10.1093/acprof:oso/9780199244843.001.0001

Clayton, N. S., Bussey, T. J., and Dickinson, A. (2003). Can animals recall the past and plan for the future? Trends Cogn. Sci. 4, 685-691. doi: 10.1038/nrn1180

Clayton, N. S., and Dickinson, A. (1998). Episodic-like memory during cache recovery by scrub jays. Nature 395, 272-274. doi: 10.1038/26216

Cooper, L. A., and Shepard, R. N. (1984). Turning something over in one's mind. Sci. Amer. 251, 106-115. doi: 10.1038/scientificamerican1284-106

Corballis, M. C. (2002). From Hand to Mouth: The Origins of Language. Princeton, NJ: Princeton University Press. doi: 10.1093/acprof:oso/9780199244843.003.0011 
Corballis, M. C. (2013). Mental time travel: a case for evolutionary continuity. Trends Cogn. Sci. 17, 5-6. doi: 10.1016/j.tics.2012.10.009

Corballis, M. C. (2017a). The evolution of lateralized brain circuits. Front. Psychol. 8:1021. doi: 10.3389/fpsyg.2017.01021

Corballis, M. C. (2017b). The Truth About Language: What it Is, and Where it Came From. Chicago, IL: University of Chicago Press. doi: 10.7208/chicago/9780226287225.001.0001

Corkin, S. (2002). What's new with the patient H.M.? Nature Rev. Neurosci. 3, 153-160. doi: $10.1038 / \mathrm{nrn} 726$

Corkin, S. (2013). Permanent Present Tense: The Man With No Memory, and What He Taught the World. London: Allen Lane.

Coudé, G., Ferrari, P. F., Rodà, F., Maranesi, M., Borelli, E., Veroni, V., et al. (2011). Neurons controlling voluntary vocalization in the macaque ventral premotor cortex. PLoS ONE 6:e26822. doi: 10.1371/journal.pone.0026822

Covington, N. V., and Duff, M. C. (2016). Expanding the language network: direct contributions from the hippocampus. Trends Cogn. Sci. 20, 869-870. doi: 10.1016/j.tics.2016.10.006

Darwin, C. (1859). On the Origin of Species by Means of Natural Selection. London: John Murray.

Darwin, C. (1871). The Descent of Man and Selection in Relation to Sex, 2nd Edn. New York, NY: Appleton. doi: 10.1037/12294-000

de Condillac, E. B. (1971). An Essay on the Origin of Human Knowledge: Being a Supplement to Mr. Locke's Essay on the Human Understanding. Gainesville, FL: Scholars' Facsimiles and Reprints. (A facsimile reproduction of the 1756 translation by T. Nugent of Condillac's 1747 essay).

De Waal, F. (2019). Mama's Last Hug: Animal Emotions and What they Teach Us About Ourselves. London: Granta.

Dediu, D., and Levinson, S. C. (2013). On the antiquity of language: the reinterpretation of Neandertal linguistic capacities and its consequences. Front. Psychol. 4:397. doi: 10.3389/fpsyg.2013.00397

Deuker, L., Bellmund, J. L., Schröder, T., and Doeller, C. F. (2016). An event map of memory space in the hippocampus. Elife 5:e16534.doi: 10.7554/eLife. 16534

Diehl, G. W., Hon, O. J., Leutgeb, S., and Leutgeb, J. K. (2017). Grid and nongrid cells in medial entorhinal cortex represent spatial location and environmental features with complementary coding schemes. Neuron 94, 83-92. doi: 10.1016/j.neuron.2017.03.004

Donald, M. (1991). Origins of the Modern Mind. London: Harvard University Press.

Dor, D. (2015). The Instruction of Imagination: Language as a Social Communication Technology. New York, NY: Oxford University Press. doi: 10.1093/acprof:oso/9780190256623.001.0001

Duff, M. C., and Brown-Schmidt, S. (2012). The hippocampus and the flexible use and processing of language. Front. Hum. Neurosci. 6:69. doi: $10.3389 /$ fnhum.2012.00069

Emmorey, K. (2002). Language, Cognition, and Brain: Insights From Sign Language Research. Hillsdale, NJ: Erlbaum. doi: 10.4324/9781410603982

Feeney, M. C., Roberts, W. A., and Sherry, D. F. (2009). Memory for what, where, and when in the black-capped chickadee (Poecile atricapillus). Anim. Cognit. 12, 767-777. doi: 10.1007/s10071-009-0236-x

Ferkin, M. H., Combs, A., delBarco-Trillo, J., Pierce, A. A., and Franklin, S. (2008). Meadow voles, Microtus pennsylvanicus, have the capacity to recall the "what", "where", and "when" of a single past event. Anim. Cognit. 11, 147-159. doi: 10.1007/s10071-007-0101-8

Fernández-Armesto, F. (2019). Out of Our Minds: What We Think and How We Came to Think it. London: Oneworld Publications.

Gärdenfors, P., and Osvath, M. (2010). "Prospection as a cognitive precursor to symbolic communication," in The Evolution of Human Language, eds R. K. Larson, V. Déprez, and H. Yamakido (Cambridge: Cambridge University Press), 103-114. doi: 10.1017/CBO9780511817755.007

Gokhman, D., Agranat-Tamir, L., Housman, G., García-Pérez, R., Nissim-Rafini, M., Mallick, S., et al. (2019). Extensive regulatory changes in genes affecting vocal and facial anatomy separate modern from archaic humans. bioRxiv 106955. doi: 10.1101/106955

Grice, H. P. (1989). Studies in the Ways of Words. Cambridge, MA: Cambridge University Press.

Hassabis, D., Kumaran, D., and Maguire, E. A. (2007). Using imagination to understand the neural basis of episodic memory. J. Neurosci. 27, 14365-11437. doi: 10.1523/JNEUROSCI.4549-07.2007
Hewes, G. W. (1973). Primate communication and the gestural origins of language. Curr. Anthropol. 14, 5-24. doi: 10.1086/201401

Hobaiter, C., and Byrne, R. W. (2011). Serial gesturing by wild chimpanzees: its nature and function for communication. Anim. Cognit. 14, 827-838. doi: 10.1007/s10071-011-0416-3

Hockett, C. F. (1960). The origins of speech. Sci. Amer. 203, 88-96. doi: 10.1038/scientificamerican0960-88

Hoffecker, J. F. (2005). Innovation and technological knowledge in the upper paleolithic. Evol. Anthropol. 14, 186-198. doi: 10.1002/evan.20066

Hoffman, K. L., and McNaughton, B. L. (2002). Coordinated reactivation of distributed memory traces in primate neocortex. Science 297, 2070-2073. doi: $10.1126 /$ science. 1073538

Igarashi, K. M., Lu, L., Colgin, L. L., Moser, M.-B., and Moser, E. I. (2014). Coordination of entorhinal-hippocampal ensemble activity during associative learning. Nature 510, 143-147. doi: 10.1038/nature 13162

Iverson, J. M., and Goldin-Meadow, S. (1998). Why people gesture when they speak. Nature 396:228. doi: 10.1038/24300

Janmaat, K. R., Polansky, L., Ban, S. D., and Boesch, C. (2014). Wild chimpanzees plan their breakfast time, type, and location. Proc. Natl. Acad. Sci. U.S.A. 111, 16343-16348. doi: 10.1073/pnas.1407524111

Jozet-Alves, C., Bertin, M., and Clayton, N. S. (2013). Evidence of episodic-like memory in cuttlefish. Curr. Biol. 23, R1033-R1036. doi: $10.1016 /$ j.cub.2013.10.021

Kabadayi, C., and Osvath, M. (2017). Ravens parallel great apes in flexible planning for tool-use and bartering. Science 357, 202-204. doi: 10.1126/science.aam 8138

Koda, H., Kunieda, T., and Nishimura, T. (2018). From hand to mouth: monkeys require greater effort in motor preparation for voluntary control of vocalization than for manual actions. Royal Soc. Open Sci. 5:180879. doi: 10.1098/rsos.180879

Krupenye, C., Fumihiro, K., Hirata, S., and Call, J. (2016). Apes anticipate that other individual will act according to false beliefs. Science 354, 110-116. doi: $10.1126 /$ science.aaf8110

Lieberman, D. E., McBratney, B. M., and Krovitz, G. (2002). The evolution and development of cranial form in Homo sapiens. Proc. Natl. Acad. Sci.U.S.A. 99, 1134-1139. doi: 10.1073/pnas.022440799

Maguire, E. A., Intraub, H., and Mullaly, S. L. (2016). Scenes, spaces, and memory traces: what does the hippocampus do? Neuroscientist 22, 432-439. doi: $10.1177 / 1073858415600389$

Martin, V. C., Schacter, D. L., Corballis, M. C., and Addis, D. R. (2011). A role for the hippocampus in encoding simulations of future events. Proc. Natl Acad. Sci. U.S.A. 108, 13858-13863. doi: 10.1073/pnas.1105816108

Martin-Ordas, G., Haun, D., Colmenares, F., and Call, J. (2010). Keeping track of time: evidence for episodic-like memory in great apes. Anim. Cognit. 13, 331-340. doi: 10.1007/s10071-009-0282-4

McBride, G. (2014). Story telling, behavior planning, and language evolution in context. Front. Psychol. 5:1131. doi: 10.3389/fpsyg.2014.01131

McCormick, C., Rosenthal, C. R., Miller, T. D., and Maguire, E. A. (2018). Mindwandering in people with hippocampal damage. J. Neurosci. 38, 2745-2754. doi: 10.1523/JNEUROSCI.1812-17.2018

Mellars, P. A. (2005). The impossible coincidence. A single-species model for the origins of modern human behavior in Europe. J. Hum. Evol. 14, 12-27. doi: 10.1002/evan.20037

Milivojevic, B., Varadinov, M., Grabovetsky, A., Collin, S. H., and Doeller, C. F. (2018). Coding of event nodes and narrative context in the hippocampus. J. Neurosci. 36, 12412-12424. doi: 10.1523/JNEUROSCI.2889-15.2016

Moser, M. B., Rowland, D. C., and Moser, E. I. (2015). Place cells, grid cells, and memory. Cold Spring Harbor Perspect. Biol. 7:a021808. doi: 10.1101/cshperspect.a021808

Müller, F. M. (1880). Lectures on the Science of Language, Vol. 1. London: Longmans, Green. Orig. pub.

Neidle, C., Kegl, J., MacLaughlin, D., Bahan, B., and Lee, R. G. (2000). The Syntax of American Sign Language. Cambridge, MA: MIT Press.

Neisser, U. (2008). "Memory with a grain of salt," in Memory: An Anthology, eds H. H. Wood and A. S. Byatt (London: Chatto \& Windus), 80-88.

Niles, J. D. (2010). Homo Narrans: The Poetics and Anthropology of Oral Literature. Philadelphia, PA: University of Pennsylvania Press. 
O'Keefe, J., and Nadel, L. (1978). The Hippocampus as a Cognitive Map. Oxford: Clarendon Press.

Panoz-Brown, D., Corbin, H. E., Dalecki, S. J., Gentry,M., Brotheridge, S., Sluk, C. M., et al. (2016). Rats remember items in context using episodic memory. Curr. Biol. 26, 2821-2826. doi: 10.1016/j.cub.2016.08.023

Patterson, F. G. P., and Gordon, W. (2001). "Twenty-seven years of project Koko and Michael," in All Apes Great and Small, Vol. 1: African Apes, eds B. M. F. Galdikas, N. E. Briggs, L. K. Sheeran, and J. Goodall (New York, NY: Kluver), 165-176. doi: 10.1007/0-306-47461-1_15

Penn, D. C., Holyoak, K. J., and Povinelli, D. J. (2008). Darwin's mistake: explaining the discontinuity between human and nonhuman minds. Behav.Brain Sci. 31, 108-178. doi: 10.1017/S0140525X08003543

Petkov, C. I., and Jarvis, E. D. (2012). Birds, primates, and spoken language origins: behavioral phenotypes and neurobiological substrates. Front. Evol. Neurosci. 4:12. doi: 10.3389/fnevo.2012.00012

Piai, V., Anderson, K. L., Lin, J. J., Dewar, C., Parvizi, J., Dronkers NF, et al. (2016). Direct brain recordings reveal hippocampal rhythm underpinnings of language processing. Proc. Natl. Acad. Sci. U.S.A. 113, 11366-11371. doi: 10.1073 /pnas. 1603312113

Pinker, S., and Bloom, P. (1990). Natural language and natural selection. Behav. Brain Sci. 13, 707-784. doi: 10.1017/S0140525X00081061

Pinker, S., and Jackendoff, R. (2005). The faculty of language: what's special about it? Cognition 95, 201-236. doi: 10.1016/j.cognition.2004.08.004

Pollick, A. S., and de Waal, F. B. M. (2007). Apes gestures and language evolution. Proc. Natnl Acad. Sci. U.S.A. 104, 8184-8189. doi: 10.1073/pnas.0702624104

Premack, D., and Woodruff, G. (1978). Does the chimpanzee have a theory of mind? Behav. Brain Sci. 4, 515-526. doi: 10.1017/S0140525X000 76512

Prüfer, K., Racimo, F., Patterson, N., Jay, F., Sankararaman, S., Sawyer, S., et al. (2014). The complete genome sequence of a Neanderthal from the Altai Mountains. Nature 505, 43-49. doi: 10.1038/nature12886

Rizzolatti, G., and Arbib, M. A. (1998). Language within our grasp. Trends Neurosci. 21, 188-194. doi: 10.1016/S0166-2236(98)01260-0

Rizzolatti, G., and Sinigaglia, C. (2010). The functional role of the parietofrontal mirror circuit: interpretations and misinterpretations. Nat. Neurosci. 11, 264-274. doi: 10.1038/nrn2805

Russon, A., and Andrews, K. (2001). Orangutan pantomime: elaborating the message. Biol. Lett. 7, 627-630. doi: 10.1098/rsbl.2010.0564

Savage-Rumbaugh, S., Fields, W. M., and Spircu, T. (2004). The emergence of knapping and vocal expression embedded in a Pan/Homo culture. Biol. Philosoph. 19, 541-575. doi: 10.1007/sBIPH-004-0528-0

Scott-Phillips, T. (2015). Speaking Our Minds: Why Human Communication Is Different, and How Language Evolved to Make it Special. Basingstoke: Palgrave Macmillan. doi: 10.1007/978-1-137-31273-0

Shepherd, S. V., and Freiwald, W. A. (2018). Functional networks for social communication in the macaque monkey. Neuron 99, 413-420. doi: 10.1016/j.neuron.2018.06.027

Simonyan, K., and Horwitz, B. (2011). Laryngeal motor cortex and control of speech in humans. Neuroscientist 17, 197-208. doi: 10.1177/10738584103 86727

Slocombe, K. E., and Zuberbühler, K. (2005). Functionally referential communication in a chimpanzee. Curr. Biol. 15, 1779-1784. doi: $10.1016 /$ j.cub.2005.08.068
Sperber, D., and Wilson, D. (2002). Pragmatics, modularity and mind-reading. Mind Lang. 17, 3-23. doi: 10.1111/1468-0017.00186

Squire, L. (2004). Memory systems of the brain: a brief history and current perspective. Neurobiol. Learn. Mem. 82, 171-177. doi: 10.1016/j.nlm.2004.06.005

Suddendorf, T. (2013). Mental time travel: continuities and discontinuities. Trends Cogn. Sci. 17, 151-152. doi: 10.1016/j.tics.2013.01.011

Suddendorf, T., and Corballis, M. C. (1997). Mental time travel and the evolution of the human mind. Genet. Soc. Gen. Psycho. Monogr. 123, 133-167.

Suddendorf, T., and Corballis, M. C. (2007). The evolution of foresight: what is mental time travel, and is it unique to humans? Behav. Brain Sci. 30, 299-351. doi: 10.1017/S0140525X07001975

Suddendorf, T., and Corballis, M. C. (2010). Behavioural evidence for mental time travel in nonhuman animals. Behav. Brain Res. 215, 292-298. doi: 10.1016/j.bbr.2009.11.044

Tanner, J. E., and Perlman, M. (2017). Moving beyond 'meaning': Gorillas combine gestures into sequences for creative display. Lang. Comm. 54, 56-72. doi: 10.1016/j.langcom.2016.10.006

Tattersall, I. (2012). Masters of the Planet: The Search for Human Origins. New York, NY: Palgrave Macmillan.

Tomasello, M. (2008). The Origins of Human Communication. Cambridge, MA: MIT Press. doi: 10.7551/mitpress/7551.001.0001

Tulving, E. (1985). Memory and consciousness. Can. Psychol. 26, 1-12. doi: $10.1037 / \mathrm{h} 0080017$

Tulving, E. (2002). Episodic memory: from mind to brain. Ann. Rev. Psychol. 53, 1-25. doi: 10.1146/annurev.psych.53.100901.135114

Venkataraman, V. V., Kraft, T. S., Dominy, N. J., and Endicott, K. M. (2017). Hunter-gatherer residential mobility and the marginal value of rainforest patches. Proc. Natl Acad. Sci. U.S.A. 114, 3097-3102. doi: $10.1073 /$ pnas. 1617542114

Warren, D. E., and Duff, M. C. (2019). Fast mappers, slow learners: Word learning without hippocampus is slow and sparse irrespective of methodology. Cogn. Neurosci. 10, 210-212. doi: 10.1080/17588928.2019.1593120

Wearing, D. (2005). Forever Today. New York, NY: Doubleday.

Wilson, A. G., Pizzo, M. J., and Crystal, J. D. (2013). Event-based prospective memory in the rat. Curr. Biol. 23, 1089-1093. doi: 10.1016/j.cub.2013.04.067

Wimmer, H., and Perner, J. (1983). Beliefs about beliefs: representation and constraining function of wrong beliefs in young children's understanding of deception. Cognition 13, 103-128. doi: 10.1016/0010-0277(83)90004-5

Young, B. J., Fox, G. D., and Eichenbaum, H. (1994). Correlates of hippocampal complex-spike cell activity in rats performing a nonspatial radial maze task. J. Neurosci. 14, 6553-6563. doi: 10.1523/JNEUROSCI.14-11-06553.1994

Conflict of Interest Statement: The author declares that the research was conducted in the absence of any commercial or financial relationships that could be construed as a potential conflict of interest.

Copyright (c) 2019 Corballis. This is an open-access article distributed under the terms of the Creative Commons Attribution License (CC BY). The use, distribution or reproduction in other forums is permitted, provided the original author(s) and the copyright owner(s) are credited and that the original publication in this journal is cited, in accordance with accepted academic practice. No use, distribution or reproduction is permitted which does not comply with these terms. 